\title{
NPI licensing in Jordanian Arabic: An argument for downward entailment and syntax-semantics interface
}

\author{
Eman Al Khalaf \\ University of Jordan, Jordan
}

\begin{abstract}
Recent work shows that downward entailment (DE) cannot be the right semantic domain that licenses negative polarity items (NPIs). Zwarts (1995), Giannakidou (1998), among others, argue that NPIs are licensed in non-veridical domains, those that do not entail or presuppose the truth of the propositions they embed. In this paper, based on empirical facts, I argue that DE theory is the right analysis for Jordanian Arabic. I propose an analysis of NPI licensing in which three components of grammar interface: syntax, semantics and pragmatics. Semantics defines the class of NPI licensors, pragmatics forces quantificational closure of NPIs, and syntax executes the licensing via AGREE between a phasal head and the NPI. The analysis contributes to the debate on what components of grammar are responsible for NPI licensing and provides a new perspective on the interface between different components of grammar.
\end{abstract}

Key words

negative polarity, free choice, syntax-semantics interface, downward entailment, Arabic

\section{Introduction}

Negative polarity items (NPIs) are linguistic expressions that must occur in special semantic domains, among which are negatives, yes-no (YN) questions, and conditionals, as exemplified below.

(1) a. John did not publish any papers last year.

b. Have you ever been to Thailand?

c. Should you have any questions, please do not hesitate to ask.

Much work has been done to characterize the domains that license NPIs. Some work proposes semantic accounts (Fauconnier, 1975; 1979; Ladusaw, 1980; Linebarger 1987; Kadmon and Landman, 1993; von Fintel 1999; Giannakidou, 2001, and many others). Other work argues for syntactic accounts (Lasnik, 1975; Progovac, 1993). Few studies propose syntactic-semantic analyses (Chierchia, 2004, e.g.). The main point of difference between syntax-based and semantics-based accounts is that the former derives licensing using syntactic principles like locality while the latter captures licensing by characterizing the semantic nature of NPIs or the semantic nature of the contexts in which they occur.

This paper contributes to the debate on which components of grammar might be responsible for NPI licensing. Citing evidence from Jordanian Arabic (JA), the paper proposes that NPI licensing involves interfacing between syntax and semantics/pragmatics: the class of NPI licensors is defined semantically, and the motivation behind licensing is quantificational closure (Chierchia, 2004), but the mode of licensing is syntactic. The rest of the paper is organized as follows. Section 1 reviews two of the main prominent studies on NPI licensing: the downward entailment and the nonveridicality theories. Section 2 presents the semantic and syntactic distribution of NPIs in JA. Section 3 presents an analysis of the facts. The last section is a conclusion.

\section{Downward Entailment Vs. Non- Veridicality}


In this section, I review two of the main prominent studies on NPI licensing, namely the downward entailment (DE) and the non-veridicality (NV) theories, showing their strengths and weaknesses. This section lays the background for my contention that $\mathrm{DE}$ analysis is the right generalization for NPI licensing in JA.

The word "negative" in "negative polarity item" is used for convenience. DE contexts include, in addition to negation, the protasis of conditionals, the restriction of a universal quantifier, the scope of antiadditive quantifiers such as no, among others. Fauconnier $(1975 ; 1979)$ and Ladusaw (1980) argue that the contexts that license NPIs share the property of being DE contexts; they allow inferences from supersets to subsets. This view has been adopted in much later work (Linebarger, 1987; Kadmon and Landman, 1993; von Fintel, 1999; Chierchia, 2004, among many others). According to the definition in (2), negation is a DE function; it allows inferences from supersets to subsets. In (3), Don't Breathe is a subset of horror movies. Replacing $a$ horror movie with Don't Breathe does not change the truth value of the sentence by virtue of negation.

(2) A function $f$ is downward entailing if for every $X$, $Y$ : if $X \subseteq Y$, then $f(Y) \subseteq f(X)$.

(3) Stacy didn't watch a horror movie last week.

$[[$ Don't Breathe $]] \subseteq[$ horror movies ]]

$\therefore$ Stacy didn't watch Don't Breathe last week.

Giannakidou (1998; 2006, and subsequent work), Zwarts (1995), among others show that the DE theory of NPI licensing is problematic, as not all the licensing domains are DE. First, NPIs are licensed in yes-no (YN) questions although they are not DE contexts. YN questions do not entail the truth from supersets to subsets as illustrated in (4b). For the rest of the paper, I use the right arrow to mean "entails", and an arrow that is preceded by NOT to mean "does not entail".

(4) a. Are you getting any vegetables from the grocery store?

b. Are you getting vegetables from the grocery store? NOT $\rightarrow$ Are you getting bananas from the grocery store?

In addition, Lin (1996), Haspelmath
(1997), Lahiri (1998), Dayal (1998), Giannakidou (1998), and many others show that some non-DE contexts may also legitimize NPIs. These include, just to mention a few, modals (5), imperatives (6), and complements of intensional verbs such as insist (7). In (6b), for instance, it is clear that imperatives do not entail truth from supersets to subsets. The same is true for all the examples that immediately follow.

(5) a. Mary will buy any book she sees.

b. Mary will read a book. NOT $\rightarrow$ Mary will read Animal Farm.

(6) a. Call anyone upon your arrival!

b. Read an article on terrorism by the end of this week! NOT $\rightarrow$ Read an article on terrorism in Europe by the end of this week!

(7) a. The government insisted that the soldiers should not let any refugees in.

b. The President insisted that undocumented immigrants should be deported. NOT $\rightarrow$ The President insisted that undocumented young immigrants should be deported.

Those non-DE contexts also license another set of items, referred to as free choice items (FCls) (Ladusaw, Dayal 2004, Jayez and Tovena, 2005, among many others).' An $\mathrm{FCl}$ is acceptable only in contexts that involve explicit or implicit quantification over alternatives; it must be assigned a different value in each possible world. More specifically, an $\mathrm{FCl}$ contains a world variable that cannot be bound by a text-level quantifier and must be bound by an intensional operator such as a modal, habitual, or generic operator (Giannakidou, 2001). Below are examples from JA. Distinct $\mathrm{FCls}$ have a complex structure. For instance, wein-ma-kan 'wherever' in (8b) has three morphemes: a wh-word wein 'where', the emphasis marker $-m a-$, and the copula $-k a n:^{2}$

$$
\begin{array}{lll}
\text { a. Laila } & \text { bidha } & \text { tiqra } \\
\text { Laila } & \text { want.3SG.F } & \text { read.3SG.F }
\end{array}
$$

\footnotetext{
' The first work to introduce FCls is Vendler, 1967. 2 Throughout the paper, I will use the following symbols in the Arabic sentences: $\underline{h}=$ voiceless pharyngeal fricative; $\underline{s}=$ voiceless alveolar fricative; $\mathrm{TH}=$ voiced interdental fricative; $\mathrm{t}=$ voiceless alveolar fricative; $\mathrm{q}=$ voiceless uvular stop; ?=glottal stop; ${ }^{c}=$ voiced pharyngeal fricative.
} 


\author{
shu-ma-kan \\ $\mathrm{FCl}$ \\ 'Laila wants to read anything.' \\ b. Laila rah tsafer weinmakan \\ Laila FUT travel.3SG.F FCl \\ 'Laila will travel anywhere.' \\ c. mi:n-ma-kan yigdar ygadim \\ FCA can.3SG.M apply \\ La-l-jam'ah \\ to-the-university \\ 'Anyone can apply to the university.' \\ d. tigdari trudi cala risalti \\ can reply.SG.F to my.letter \\ eimta ma-kan \\ whenever \\ 'You can respond to my letter whenever \\ (you want).'
}

$\mathrm{FCls}$ are restricted by non-episodicity (Giannakidou, 2001); that is, they appear only in contexts that make no reference to a particular event. This is why negative episodic statements, as well as positive ones, do not license FCls; these contexts do not refer to a specific event:

\section{(9) "Ali ma shaf mi:n-ma-kan Ali NEG saw.3SG.M $\mathrm{FCl}$ \\ '*Ali did not see whoever.'}

The distinction between NPIs and FCls will become significant to the discussion in section 3 when I show that in JA some items are ambiguous between NPIs and FCls.

To characterize the wide range of contexts that license NPIs, Giannakidou (1998), Zwarts (1995), among others, propose that NPIs are licensed in the domain of non-veridical (NV) operators. An NV operator does not entail the truth of the proposition it embeds. If the truth of a proposition $p$ is not entailed in the domain of an operator $F$, then $F$ is a non-veridical operator. The NV theory explains the ungrammaticality of NPIs in the context of positive existentials, for instance. These contexts do entail the truth of their propositions. In $(10 \mathrm{~b})$, it is entailed that there is a mouse in the basement, which is why any is unacceptable here.

(10) a. *There is any mouse in the basement.

b. $\exists x \exists w[x$ is a mouse and $x$ is in the basement in $\mathrm{w}]$.

The NV theory also captures NPI licensing in DE contexts because DE contexts are also NV. In (11a) and (12a), any is licensed because the negative operator and the protasis of the conditional do not entail the truth of the propositions they embed, respectively.

(11) a. The lawyer did not find any witness to testify in favour of her client.

b. $\exists \mathrm{x} \exists \mathrm{w}[\mathrm{xis}$ a witness and the lawyer found $x$ to testify in favour of her client in $\mathrm{w}]$.

(12) a. If the government passes any laws to ban refugees from entering the country, hundreds of protests will erupt across the country.

b. $\exists x \exists w[x$ is a law and the government will pass $x$ this month in $w]$.

The NV theory also explains NPI licensing in $\mathrm{YN}$ questions. $\mathrm{YN}$ questions are nonveridical because they do not entail the truth of the proposition, as shown in (13) for (4a) above.

(13) $\neg \exists x \exists w[x$ is a vegetable and you are getting $x$ from the grocery store in w].

The NV theory, however, does not predict the pattern of NPI licensing in some veridical contexts (Horn, 1996; Giannakidou, 2006). For instance, English any and a class of NPIs called minimizers (e.g., a red cent) are licensed in the scope of only, which is a veridical context. In (14a), the proposition that only scopes over is entailed to be true; still, the sentence licenses the NPI. The same applies to (15a), in which a minimizer is licensed in the scope of only.

(14) a. Only John read anything.

b. $\exists x \exists w[J o h n$ read $x$ in $w]$.

(15) a. Only John gave a red cent to charity.

b. $\exists x \exists w$ [ $x$ is a red cent and John gave $x$ to charity in $w$ ].

Horn (1996) argues that NPIs are licensed in the scope of only by virtue of the negative assertion it invokes. Only John ate a vegetable asserts that nobody other than John ate a vegetable. The negative indefinite is what licenses the NPI here. Giannakidou (2006) explains the behaviour of only by assuming a "rescuing" mechanism. An expression is rescued in the scope of a veridical operator if the proposition's global 
context $\mathrm{C}$ makes a proposition $\mathrm{S}$ that has an NV operator available. The global context includes a set of propositions that arise from an expression without necessarily being entailed by it. In (16), only invokes negated focus alternatives that rescue the NPI.

(16) a. Only John read anything.

b. The sentence presupposes that John read something $(=(=\exists X \exists W[$ John read $x$ in $w])$ and asserts that no one else read anything $(=\forall x$.xisnotJohn $\rightarrow \neg \exists$ y.xready)

The rescuing strategy, nonetheless, does not seem to be an attractive explanation of the facts. It is not clear what factors control this strategy, and why other veridical contexts do not allow it. As shown above, both DE and NV theories have scopal issues: NPIs appear in domains outside the scope of the domains each of the theories defines as NPI licensing. In the next section, I show that JA does not allow NPIs in non-DE domains, making the DE theory superior to the NV theory. In order to achieve this goal, two main issues need to be addressed: (i) NPI licensing in $\mathrm{YN}$ questions, which are non$\mathrm{DE}$, and (ii) NPI licensing in other nonveridical contexts that also license free choice items. In particular, I will show that JA does not license NPIs in YN questions, and licenses NPIs in non-DE contexts only when they have free-choice reading. This will leave us with the generalization that NPIs are only licensed in DE contexts in JA.

\section{The distribution of NPIs in JA}

JA shows two classes of NPIs: (i) NPIs that are only licensed in the domain of sentential negation, and (ii) NPIs that are licensed in the domain of DE operators. Benmamoun (1997) introduces two NPIs from Moroccan Arabic, the JA equivalent of which are ishi 'thing' and hada 'person':

(17) jibt-i ishi $m a^{c}=i k$

bring-2SG.F thing with-2SG.F

$\min$ is-su:g?

from the-market

'Have you brought anything from the market with you?'

(18) shift $\underline{\text { hada/ishi }}$

see.2SG.M person/thing

ghari:b bi-l-karaj?

suspicious in-the-garage

'Have you seen anyone/anything

suspicious in the garage?'
These items do not seem to be NPIs, as they have free distribution, which means that they are not sensitive to negative polarity. Below are some examples from Modern Standard Arabic (but the same holds for JA):

(19) Ishtara Ali shay?-an buy.3M.SG Ali thing-ACC $\min$ al-su:q the-market

'Ali bought something from the market.'

(20) hunak ahad-un qad tasalala ila EXIS person-NOM PERF sneak in mazracat-i=na farm-GEN=1 pl 'There is someone who has sneaked in our farm.'

(21) Fi hada itaSal $m a^{c}=a k$ EXIS person call.3SG.M with=2SG.M il-yoom the-day 'There is someone who has called you today.'

(22) Salma haka-t inha simca-t ishi Salma say that heard.3SG.F thing bi-I-hadi:qa in-the-garden 'salma said that she heard something in the garden.'

In terms of the typology proposed by Nam (1994) and van der Wouden (1994), the first class is referred to as strongest NPIs, whereas the second one is called weak NPIs. ${ }^{3}$ Hatta-lauu 'even-if' is a strongest $\mathrm{NPI}:$

(23) Salma ma nasharat hatta-lauu ktab S. NEG publish-3SGF even-if book 'Salma didn't publish any book.'

(24) *lauu lag-at Salma hatta-lauu If find-3SG.F Salma even-if waTHi:fah ma safar-at job NEG travel-3SG.F 'If Salma found any job, she wouldn't leave the country.'

(25) *jar=na ishtara neighbor=1 PL.POSS buy.3SG.M

${ }^{3} \mathrm{JA}$ does not exhibit a third class in Nam and van der Wouden's classification, which they call strong NPIs, those that are licensed in the domain of anti-additive operators. I will not seek to explain this gap in this paper. 
hatta lauu sayyarah?

even-if car

'Did our neighbour buy any car?

(26) "wala talib b-il-qisim No student in-the-department katab hatta-lauu bahth wrote even-if paper 'No student in the department wrote any paper.'

(27) *koll elmuatin-i:n ?illi khadamu All the.citizens who serve.3PL.M hatta-lauu shaher bil-jaish even-if a.month in-the-army t-karam-u PASS-honor-3PL.M 'All the citizens who had served in the army at any time were honoured.'

Weak NPIs, on the other hand, are licensed in all DE contexts, including sentential negation. Examples of weak NPIs in JA are ayy 'any' and lauu 'even'.

(28) Nuha ma bid-ha Nuha NEG want-3SG.F buy ayy/lauu fustan any/even dress 'Nuha does not want to buy any dress.'

(29) idha Kamal safar la ?ayy/l-lauu If Kamal travel to any/even dawlah rah yji:b hadiyah country fut bring.3SG.M present la-?umm $=$ uh for-mother=3SG.M.POSS 'If Kamal travels to any country, he will bring a present for his mother.'

(30) koll iț-tullab ?illi cindhum

All the-students who LOC ayy su?al $\quad \mathrm{rraj}^{\mathrm{c}}-\mathrm{u}$ any question report.to-3PL.M al-mudarris the-teacher

'All the students who have any questions should report to the teacher's office.'

(31) wala maktabah fi Istanbul No library in Istanbul tbi:c ayy ktab bi-l- al-carabiyah sell any book in-Arabic

'No library in Istanbul sells any/even a book in the Arabic language.'

Weak NPIs also include minimal nouns, referred to as minimizers, such as fils ahmar 'red cent' (owing to Alsarayreh
(2012)). Minimizers can be verbal, like 'abbar 'give a damn'. These also appear in all DE contexts:

(32) Ali ma dafac Ali NEG pay.PST.3SG.M cent red la-zakah to-the-charity 'Ali did not pay a red cent to the charity.'

(33) Idha Ali dafac fils ahmar If Ali pay.SG.M cent red la-zakah, al-hukumah rah for-charity the.government FUT $t i-{ }^{c} f i=h$ min al-THarayib exempt=3SG.M from taxes 'If Ali pays a red cent as a donation, he will be tax exempt.'

(34) koll al-muatin-i:n ?illi dafac-u fils all the-citizens who pay cent ahmar lalhukumah safaru red to.the.government travel 'All the citizens who paid a red cent to the government left the country.'

(35) Wala wahad 'abbar ishacit

No one give.a.damn.about rumour Innuh fi nifayat nawawiyah bil-balad that EXPL waste nuclear in-country 'No one gave a damn about the the rumour that there is nuclear waste in the country.'

Unlike many languages, including English, JA does not license NPIs in YN questions (36). NPIs are not licensed in embedded questions either (37).

$$
\begin{aligned}
& \text { *qara?t-i ayy ktaab } \\
& \text { read-2SG.F any book } \\
& \text { 'Did you read any book?' }
\end{aligned}
$$

b. ??jibt-i ayy ishi macik bring.2SG any thing with.2SG.F min is-su:g?

from the-market 'Have you brought anything from the market?'

(37) *Laila sa?alat idha qara?t ?ay ktab Laila asked if read-1SG any book 'Laila asked whether I read any book?'

The behaviour of $\mathrm{YN}$ questions in Arabic is not expected given that many languages do license NPIs in this domain. There are two ways this can be explained. First, 
Arabic YN questions take the form of a statement, which might be the reason of the lack of licensing. The second is to assume that YN questions themselves are not licensing domains at all. However, some languages allow NPIs in YN questions because of the negative entailment a YN question invokes, as suggested by Baker (1970).

Weak NPIs may also appear in non-DE contexts, including modals, imperatives, and the complement of intensional verbs (e.g., want):

(38) Sami bidd-u Muna tishtariluh Sami want-3 Muna buy.for.him ayy ktab any/even book

'Sami wants Mona to buy any book for him.'

(39) kol ittullab lazem yigadm-u all the-students must give.3PL.M

?ay tabaruc la.tarmi:m

any donation for.renovation

il-madrasah

theschool

'All students must give any donation for the school's renovation.'

(40) ru:h ihki mac ayy/lauu wahad go.IMP talk.IMP with any/even one ta $y s a^{c} d=a k$

to help.INF.3SG.M=3SG.M

'Go talk to anyone to help you.'

The NPIs that appear in these non-DE domains are, in fact, semantically distinct from those that occur in the DE contexts. For one, native speakers report that when ayy and lauu occur in non-DE contexts, their meaning involves vagueness, variation, and/or free choice. For instance, sentence (41a) can be paraphrased as 'if there is a book, Muna will buy it, no matter what it is', as formally represented in ( $41 b)$.

(41)a. Muna rah ti-shtari ayy ktab Muna fut buy any book 'Muna will buy any book.'

b. $\nvdash \mathrm{W}[\exists x[B O O K(x)(w) \rightarrow B \cup Y(m$, $x)(w)]$

'For all $w$, there exists $x$ such that, if $x$ is a book, Mary will buy $x$ in w.'

Choice and variation do not arise when ayy and lauu appear in DE contexts, though. Instead, they are interpreted as existential quantifiers with no world variable. That is, they do not invoke possible world readings.
(42) a. Muna ma ishtara-t ay ktab Muna NEG buy any book 'Muna did not buy any book.' b. $\neg \exists x[B \cup Y(m, x)]$

'There is no book $x$, such that Muna bought $x$.'

I take this difference to indicate that ayy and lauu can be NPIs in some contexts and $\mathrm{FCls}$ in others, following previous work (e.g., Dayal's [2004] analysis of any). I assume that the FC versions of ayy and lauu have a null morpheme, which gives them their intensional nature. This morpheme introduces a world variable that must be bound by a special operator that can only arise in specific contexts, like imperatives, modals, intensional verbs, among others.

The ambiguity analysis predicts that in contexts that give rise to alternatives like generics, habituals, directives and modality, ayy and lau give an FC reading as opposed to the existential reading an NPI gives. In (43a), the (null) generic operator (which is assumed to be operative at the Logical Form [LF]) licenses the FC ayy. I assume that there is a null world variable in ayy that is bound by this generic operator (43b).

(43) a. ayy shakhs y yib as-safar any person like the-traveling 'Any person likes traveling.'

b. $\forall w[\exists x L I K E(x, t)(w)]]$ :in each possible world, there is a person (not specific) such that he/she likes traveling.

c. $\exists x[L I K E(x, t)]$ : there exists a person in the actual world such that this person likes traveling.

Note that the existential reading (i.e., the NPI reading) here is unavailable because of the lack of a DE operator (43c). In contrast, in DE contexts, ayy and lauu are interpreted as existentials, as we have seen in various examples above.

Ambiguity may arise if two operators take scope over the item: one is a Qoperator (modal or generic) and the other a DE operator, as illustrated below.

(44) a. Muna ma rah tsafir 
Muna NEG FUT travel.3SG.F

l-ayy dawlah

to-any country

'Muna will not travel to any country.'

b. $\neg \exists x[T \operatorname{RAV} E L(m, x)]$ : there does

not exist a country in the actual world such that Muna will travel to that country.'

c. $\forall w^{t} \subset w, \exists x\left[\neg \operatorname{TRAVE} L(m, x)\left(w^{t}\right)\right]$, in each world in a subset of possible worlds that is compatible with Muna traveling to a country, there exists a country such that Muna will not travel to it.'

Turning to syntactic restrictions, there seems to be a locality restriction on NPI licensing of NPIs in JA. The strongest NPI hatta-lauu that appears in an embedded clause cannot be licensed by matrix negation $(44 b, 45 b)$. Only negation in the embedded clause makes this NPI licit (44a, 45a).

\section{(45) a. Salma gala-t $\left[_{c p} i n n=u\right.$ Ali $m a$}

Salma say [cp that=it Ali NEG Ishrara hatta-lauu ktab min buy even-if book from il-bazaar ] the-bazaar ] 'Salma said that Ali did not buy any book from the bazaar.'

b. *Salma ma gala-t [innu Ali

Salma NEG say that Ali ishrara hatta-lauu ktab min buy even-if book from il-bazaar] the-bazaar ]

'Salma did not say that Ali bought any book from the bazaar.'

(46) a. Ali biyfakr innu Salma ma rah Ali think that Salma NEG fut tlagi hatta-lauu waTHi:fah find even-if job 'Ali does not think that Salma will find any job.'

b. *Ali ma biyfakr innu Salma rah Ali neg think that Salma fut. tlagi hatta-lauu waTHi:fah find even-if job 'Ali does not think that Salma will find any job.'

Weak NPIs also require strict locality although generally weak NPIs crosslinguistically do not (e.g., English any). An embedded minimizer requires a local $D E$ operator. A matrix DE operator cannot do the licensing (47b). The same facts hold when the licenser is the anti-additive quantifier wala 'no' (48b).

(47) a. Rula tfakir [cp inn=u Sami ma Rula think [cp that=it Sami NEG cabbar THyu:f-uh give.damn .about guests=3SG.M bi-l-haflah] in-the-party ] 'Rula thinks that Sami did not give a damn about his guests at the party.'

b. *Rula ma tfakir [cp inn=u Sami Rula NEG think [cp that=it Sami cabbar THyu:fuh give.a.damn.about guests=3SG.M bi-I-haflah ] at-the.party] 'Rula does not think that Sami gave a damn about his guests at the party.'

(48) a. wala talib cabbar kalaam No student gave.damn.about speech al-istadh 'an al-inTHibat the-teacher.m about the-discipline 'No student gave a damn about the teacher's speech about (maintaining) discipline.'

b. "[C ${ }_{C P 2}$ wala talib haka $\left[_{C P 1}\right.$ in $=n u$ no student said [cpl that=it Muna 'abbar-at Jane]] Muna give.a.damn.about Jane]] 'No student said that Muna gave a damn about Jane.'

(49) a. Rula gala-t [cp inn=u Sami ma Rula say [cpthat=it Sami NEG dafac ayy/lauu sadagah ]

pay any/even donation ]

'Rula said that Sami has not donated anything.'

b. "Rula ma gala-t [cp inn=u Sami Rula NEG say-3SG.F [cp that=it Sami dafac ayy/lauu sadagah ] pay.3SG.M any/even donation] 'Rula did not say that Sami had given any donation.'

The same locality constraint applies to the restriction of the universal quantifier koll 'all'. Note that while it is grammatical for a weak NPI to appear in a clause that restricts the universal quantifier (50a), it is ungrammatical for it to appear in a clause embedded further in the restricting clause (50b).

(50) a. koll it-talibat [CPP? illi sarafin All the-student.PL.F [ 


\section{girsh ahmar] 'ala elmashru:c cent red on the.project rah yi-tcawaTH-in]}

fut PASS-compensate-3PL.F ]

'All the students who spent a red cent on the project will be reimbursed.'

b. *[срз koll al-banat [ [ ${ }_{C 2}$ ?illi Maha [all the-girl.PL.F [ ${ }_{\mathrm{CP} 2}$ whom Maha fakara-t[ cPI $_{1}$ inn $=u$ h 'abbar-in Sami think [cp that give.damn.about Sami tzawaj-in]]] get.married.PST-3PL.F]]]

'All the girls that Maha thought that (they) gave a damn about Sami got married.'

To summarize, JA has two classes of NPIs: strongest and weak. The former is licensed in the domain of sentential negation, whereas the latter is licensed in all DE domains. Weak NPIs have FC counterparts that are licensed in the nonDE domains. Crucially, YN questions do not license NPIs in JA. This makes DE the best semantic characterization of the licensing domains. As for syntactic constraints, all NPIs in JA, whether strongest or weak, require a local licensor. I summarize the semantic distribution of JA's NPIs and FCls in Table 1.

\begin{tabular}{|c|c|c|c|c|}
\hline & $\mathbf{1}$ & $\mathbf{2}$ & $\mathbf{3}$ & $\mathbf{4}$ \\
\hline Episodic Negation & $\sqrt{ }$ & $\sqrt{ }$ & $\sqrt{ }$ & $*$ \\
\hline Protasis of Conditional & $*$ & $\sqrt{ }$ & $\sqrt{ }$ & $*$ \\
\hline Restriction of koll all'. & $*$ & $\sqrt{ }$ & $\sqrt{ }$ & $*$ \\
\hline DE-Quantifier & $*$ & $\sqrt{ }$ & $\sqrt{ }$ & $*$ \\
\hline Episodic YN Qs & $*$ & $? ?$ & $? ?$ & $*$ \\
\hline Imperatives & $*$ & $*$ & $*$ & $\sqrt{ }$ \\
\hline Modals & $*$ & $*$ & $*$ & $\sqrt{ }$ \\
\hline Directives & $*$ & $*$ & $*$ & $\sqrt{ }$ \\
\hline Intensional Verbs & $*$ & $*$ & $*$ & $\sqrt{ }$ \\
\hline Cenerics & $*$ & $*$ & $*$ & $\sqrt{ }$ \\
\hline Habituals & $*$ & $*$ & $*$ & $\sqrt{ }$ \\
\hline
\end{tabular}

Table 1: The Semantic Distribution of NPIs and FCls in JA (1=hatta-lauu, 2=minimizers, $3=\mathrm{NPI}$-ayy/lauu, $4=\mathrm{FC}$ ayy/lauu)

\section{Analysis}

Before I propose an analysis of NPI licensing in JA, I will provide the necessary background. Kadmon and Landman (1993) propose that any widens the quantificational domain that would otherwise be considered. Domain widening leads to strengthening in the scope of a DE operator. Widening in nonlicensing domains leads to weakening. In (51b), any widens the domain of friends that the hearer should consider unnecessarily, causing the sentence to be weak or less informative.

(51) a. Julia invited a friend to her graduation ceremony.

b. "Julia invited any friend to her graduation ceremony.

On the other hand, in DE contexts, domain extension makes the statement stronger and more informative. In (52), any widens the domain of friends to include all sets of possible friends, and by negating this widened domain, the proposition that 'Julia did not invite a friend' becomes stronger.

(52) Julia did not invite any friend to her graduation ceremony.

Chierchia (2004) proposes that the domain expansions triggered by the NPI must be universally closed, and this closure must lead to strengthening, making the proposition more informative.

\section{(53) Strengthening/blocking}

Domain expansions must be universally closed. Such closure must lead to strengthening with respect to the meaning of the plain indefinite. (Chierchia, 2004, 76, 113)

Chierchia points out that although strengthening is a pragmatic effect that should be checked globally, the actual licensing of the $\mathrm{NPI}$ /quantificational closure is accomplished syntactically, respecting locality restrictions. The licensing takes the form of feature checking: a head with a [+DE] feature checks that feature on the NPI via AGREE (Chomsky, 2001). This assumption is not new. As brought to my attention by an anonymous reviewer, van der Wouden (1994, p.58) also makes a similar assumption about Dutch; he assumes that the embedded clause under matrix negation is anti-additive, which is what the analysis proposed here does: it endows the clause in the scope of negation/DEoperator with some semantic property/feature. Also, as pointed out to me by the same anonymous reviewer, the analysis here has similarities to Laka (1994) in which it is assumed that negative predicates (e.g., deny) select a clausal complement in which the complementizer is endowed with [+NEG] feature.

To illustrate in English, in (54a), two [+DE] feature-bearing heads take scope 
over the NPI; widening does not lead to strengthening because the global domain is positive; still, the NPI survives. Here the $\mathrm{NPI}$ is licensed by the most local [+DE] bearing head, which is the embedded negation.

(54) (Chierchia, 2004, 73, (107))

a. It is not true that there aren't any potatoes

b. Value onstandarddomain: $\neg \exists D x[$ potatoes $(x)$

c. Value onwideneddomain: $\neg \neg \exists g(D) \times[$ potatoes $(\mathrm{x})]$

Turning to JA, as shown in section 3 , NPI licensing in JA is restricted by syntactic locality, whether the NPI is strongest or weak. To capture the locality, I will assume that CP is a phase (Chomsky, 2001) and quantificational closure is accomplished by AGREE between the phasal head $C$ and the NPI. Structures are built countercyclically, in a top-down fashion. Two instances of AGREE occur during the derivation. The first is AGREE between the phasal head and the lexical item that triggers the licensing. The second AGREE occurs between $C$ and the NPI, resulting in checking of undefined features on the NPI. I define the licensing condition of NPIs in JA below:

\section{(55) Licensing of NPIs in JA}

a. Weak NPIs are licensed in the local domain of a $\mathrm{C}$ with [+DE] feature.

b. Strongest NPIs are licensed in the local domain of a $\mathrm{C}$ with $[+\mathrm{DE},+\mathrm{NEG}]$ features.

c. $\mathrm{C}$ acquires the $[+\mathrm{NEG}]$ or $[+\mathrm{DE}]$ feature via AGREE with a local head with the relevant feature, or inherently if it is a conditional C (in the protasis).

As is clear from the condition above, the difference between a domain that licenses a weak NPI and one that licenses a strongest NPI is in the [+NEG] feature, which provides a further restriction of the licensing domain. Assuming a doublefeature system is not unprecedented. Nishiguchi (2009) assigns three features: strong, medium and weak to strong negation (see Nishiguchi's original work for details). ${ }^{4}$ To show how the analysis works for (23), which I repeat below in (56), the NPI is a strongest NPI that must

${ }^{4}$ This fact was brought to my attention by an anonymous reviewer. be locally licensed in the scope of negation. I assume that the sentence is a CP. C carries the licensing feature, which it gets via AGREE with the negative marker $m a$, as shown in Figure 1 below.

\section{(56) Salma ma nashara hatta-lauu \\ Salma NEG publish.3SG.F even-if ktab \\ book \\ 'Salma didn't publish any book.'}

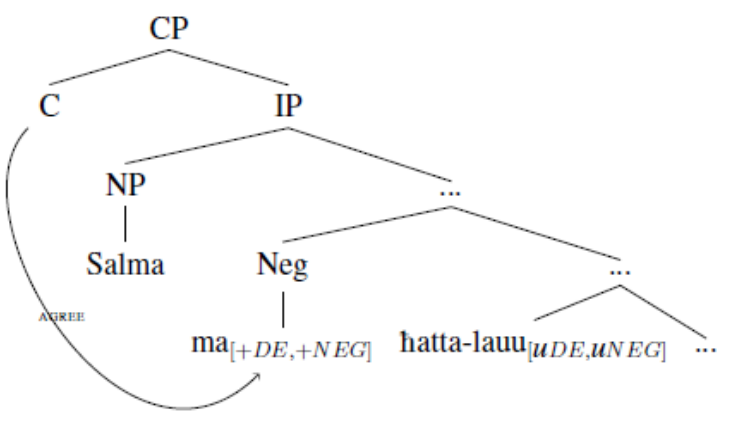

Figure 1: NPI Licesning via AGREE

Then, $C$, which is now valued for [+DE, +NEG] features enters in AGREE with the NPI, checking its undefined features. This agreement results in quantificational closure, as illustrated in Figure 2.

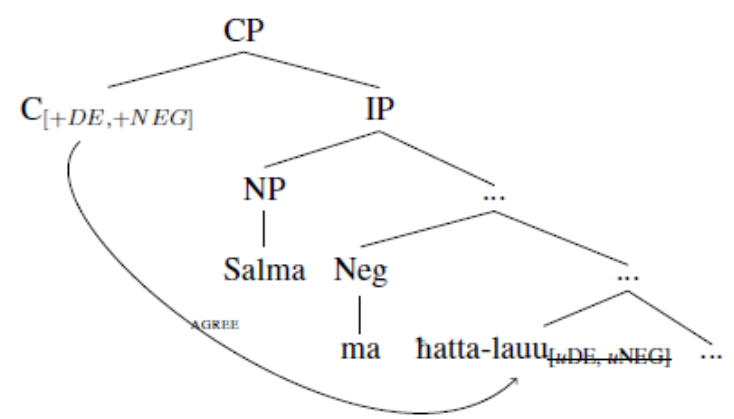

Figure 2: NPI Licensing via AGREE

A non-local licensor does not license an $\mathrm{NPI}$. A C with NPI licensing features does not go beyond the CP phase it heads. To illustrate this for (45b), reproduced below for convenience, after $C$ values its features by agreeing with the matrix negative marker, AGREE with the NPI fails to occur because there is an intervening phasal node, causing the derivation to crash.

(57) *Salma ma gala-t lcp $_{\text {inn }}=u$ Ali ishrara Salma NEG say [cp that=it Ali buy hatta-lauu ktab min il-bazaar] even-if book from the-bazar] 'Salma did not say that Ali bought 
any book from the bazaar.'

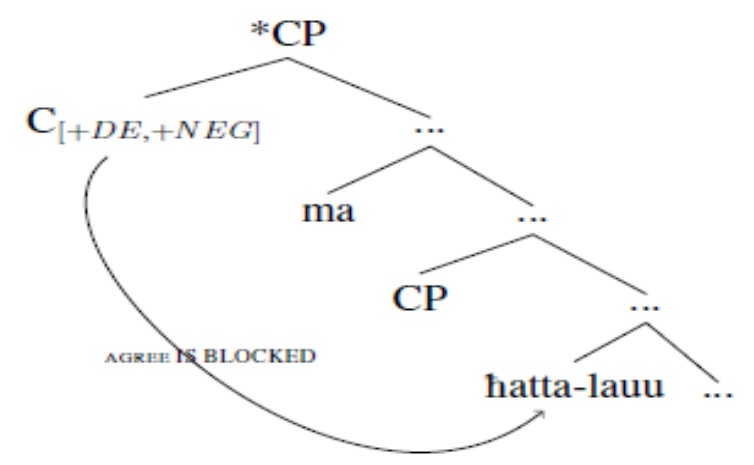

Figure 3: Locality in NPI Licensing

If we turn to other DE domains, like the restriction of the universal quantifier koll 'all', the locality of NPI licensing can also be explained. For example, the licensing mechanism I propose derives the contrast between (58a) and (58b).

(58) a. koll al-banat ?illi saraf-in girsh all the-girls who spent.3PL.F cent ahmarhidr-in al-haflah ]

red attend.PST-3PL.M the-party

'All the girls who spent a red cent attended the party.'

b. "[koll albanat ?illi hidr-in alhaflah]

All the.girls who attend the.party saraf-in girshahmar ] spent-3PL.F cent red ]

'all the girls who attended the party spent a red cent.'

In (58a), the NPI licensing context is the CP that restricts the domain of the universal quantifier. The complementizer of the restriction values its downward entailment feature by agreeing with the universal quantifier koll, as diagrammed below.

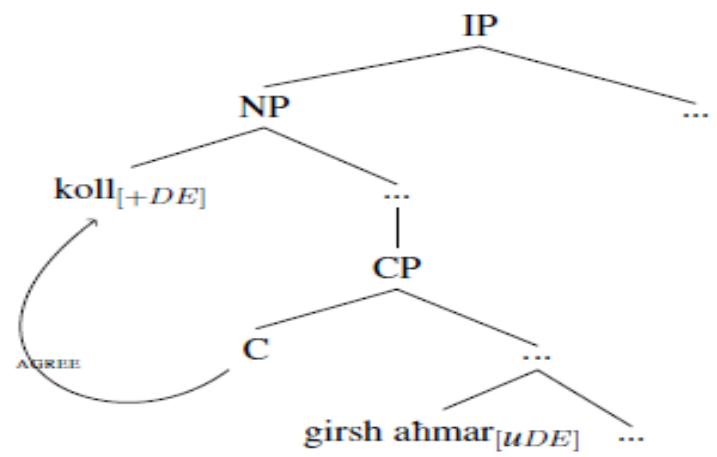

Figure 4: AGREE between the Universal Quantifier and C

The C, in turn, agrees with the NPI inside the restricting clause, resulting in quantificational closure (Figure 5).

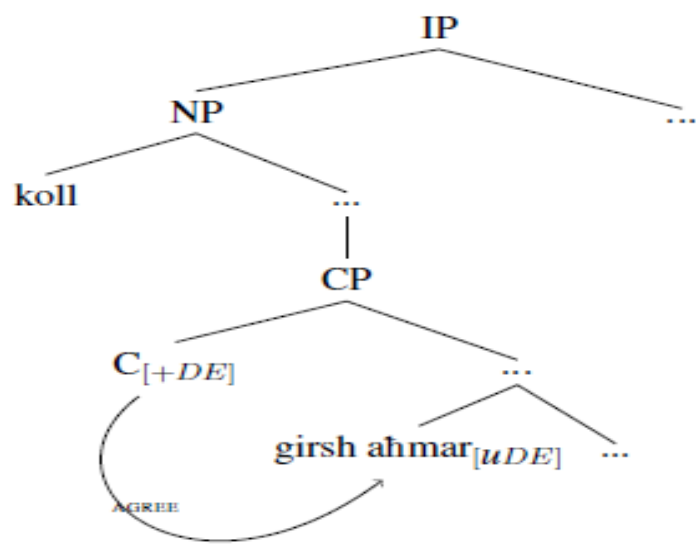

Figure 5: AGREE between C and the NPI

NPI licensing is impossible in (58b), on the other hand; the $C$ of the restricting clause cannot license an NPI in the matrix clause because it falls outside the phase of the licensing $C$.

The analysis derives NPI licensing in all the other DE domains in the same way. In the protasis of the conditional, for instance, the NPIs are licensed by a $C$ with an inherent [+DE] feature. I assume that along with the commonly assumed conditional feature [+COND] that marks the protasis, there is also a [+DE] feature. This explains why the consequent clause does not license NPIs (59); it lacks such a feature.

(59) *idha Ali safar alsucu:diyah, If Ali travelled.3SG.M Saudi.Arabia Rah yi-dfac fils ahmar lal-zakah FUT pay cent red for-the-donation '*If Ali travelled to Saudi Arabia, he will pay a red cent as a donation.'

Licensing in the protasis is also restricted by locality. It is ungrammatical for a weak NPI to occur in a clause embedded within the protasis (60). Again, this restriction is captured by my analysis by allowing only the phasal node to check the NPI within the phase.

(60) *idha Aligal inn.u dafac fils if Ali said.3SG.M that.pay.3SG.M cent ahmar ka-zakah, mish rah red as-donation NEG FUT a-Sadig=uh PRES.1SG-belive=3SG.M

'If Ali said that he will pay a red cent as a donation, I will not believe him.'

The analysis proposed above provides a simple account of the locality restrictions 
in JA. It also shows the different components of the grammar interface in NPI licensing: semantics, pragmatics and syntax. Semantics defines the class of NPI licensors; pragmatic principles motivate the need for quantificational closure (informativeness); syntax forces locality (AGREE and phases).

\section{Conclusion}

To conclude, in this paper I have demonstrated that the DE theory better accounts for the distribution and licensing of NPIs in JA. That YN questions do not license NPIs in JA and my contention that the occurrences of some NPIs in non-DE domains are $\mathrm{FCls}$ give the $\mathrm{DE}$ theory a better standing than the NV theory for JA. The analysis also shows that different components of the grammar interface in the licensing of NPIs, which is an issue that is yet to be investigated for many other phenomena that fall in the area between syntax and semantics or pragmatics. There is still the question of whether this analysis can be generalized to other languages, which I leave for future research.

\section{Acknowledgment}

I thank Benjamin Bruening, Satoshi Tomioka, and two anonymous TIL reviewers for their helpful comments. I also thank Akram Alshadaydeh for his help.

\section{References}

ALSARAYREH, A., 2012. The licensing of negative sensitive items in Jordanian Arabic. Ph.D. thesis, University of Kansas.

BAKER, C. L., 1970. Double negatives. Linguistic Inquiry, vol. 1, pp. 169-186.

BENMAMOUN, E., 1997. Licensing of negative polarity items in Moroccan Arabic. Natural Language and Linguistic Theory, vol. 15, pp. 263-287.

CHIERCHIA, G., 2004. A semantics for unaccusatives and its syntactic consequences. In: A. Alexiadou, E. Anagnostopoulou, and M. Everaert, eds., The unaccusativity puzzle: Explorations of the syntax-lexicon interface. Oxford: Oxford University Press, pp. 22-59.

CHOMSKY, N., 2001. Derivation by phase. In: M. Kenstowicz, ed., Ken Hale: A life in language. Cambridge, MA: MIT Press, pp. 1-52.

DAYAL, V., 1998. Any as inherently modal. Linguistics and Philosophy, vol. 21, pp. 433-476.

DAYAL, V., 2004. The universal force of free choice Any. Linguistic Variation Yearbook, vol. 4, pp. 5-40.

FAUCONNIER, G., 1975. Polarity and the scale principle. Chicago Linguistics Society, vol. 11 , pp. 188-199.

FAUCONNIER, G., 1979. Implication reversal in natural language. In: F. Guenthner and S. J. Scmidt, eds., Formal semantics and pragmatics for natural languages. Dordrecht: Reidel, pp. 289-302.

VON FINTEL, K., 1999. NPI-licensing, Strawson-entailment, and context-dependency. Journal of Semantics, vol. 16, pp. 97-148.

GIANNAKIDOU, A., 1998. Polarity sensitivity as (non)veridical dependency. Amsterdam: John Benjamins.

GIANNAKIDOU, A., 2001. The meaning of free choice. Linguistics and Philosophy, vol. 24, pp. 659-735.

GIANNAKIDOU, A., 2006. Only, emotive factive verbs, and the dual nature of polarity dependency. Language, vol. 82, pp. 575-603.

HASPELMATH, M., 1997. Indefinite pronouns. Oxford: Clarendon.

HORN, L., 1996. Exclusive company: Only and the dynamics of vertical inference. Journal of Semanticism, vol. 13, pp. 1-40.

JAYEZ, J. and TOVENA, L. M., 2005. Free choiceness and non-individuation. Linguistics and Philosophy, vol. 28, pp. 1-71.

KADMON, N. and LANDMAN, F., 1993. Any. Linguistics and Philosophy, vol. 15, pp. 353-422. LADUSAW, W., 1980. Polarity sensitivity as inherent scope relations. New York: Garland.

LAHIRI, U., 1998. Focus and negative polarity in Hindi. Natural Language Semantics, vol. 6, pp. $57-123$.

LAKA, I., 1990. Negation in syntax: On the nature of functional categories and projections. Ph.D. Thesis, MIT. MIT Working Papers in Linguistics: Cambridge, MA.

LASNIK, H., 1975. On the semantics of negation. In: D. J. Hockney, ed., Contemporary research in philosophical logic and linguistic semantics. Dordrecht: Reidel, pp. 279-311.

LIN, J., 1996. Polarity licensing and wh-phrase quantification in Chinese. Ph.D. thesis, 
University of Massachusetts, Amherst. Distributed by GLSA.

LINEBARGER, M., 1987. Negative polarity and grammatical representation. Linguistics and Philosophy, vol. 10, pp. 325-387.

NAM, S., 1994. Another type of negative polarity. In: K. Makoto and C. Pinon, eds., Dynamic, polarity and quantification. CSLI: Stanford, pp. 3-15.

NISHIGUCHI, S., 2009. Bipolar items and attitude predicates. In: I. Kwon, H. Pritchett, and J. Spence, eds., Proceedings of the Thirty-Fifth Annual Meeting of the Berkeley Linguistics Society. Berkeley Linguistics Society: CA, USA, pp. 424-435.

PROGOVAC, L., 1993. Negative polarity: Entailment and binding. Linguistics and Philosophy, vol. 16, pp. 149-180.

VENDLER, Z., 1967. Linguistics in philosophy. Ithaca: Cornell University Press.

VAN DER WOUDEN, T., 1994. Negative contexts. Ph.D. Thesis, University of Groningen.

VAN DER WOUDEN, T., 1994. Polarity and illogical negation. In: K. Makoto and C. Pinon, eds., Dynamic, polarity and quantification. CSLI: Stanford, pp. 17-48.

ZWARTS, F., 1995. Nonveridical contexts. Linguistic Analysis, vol. 25, pp. 286-321.

Author's address and contact details

Dr. Eman Al Khalaf

Department of English Language and Literature

School of Foreign Languages

University of Jordan

Queen Rania Street

Amman, Jordan 11942

E-mail: e.alkhalaf@ju.edu.jo 